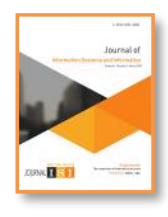

Vol. 1, No. 1, March 2019 e-ISSN: 2656-4882 p-ISSN: 2656-5935

http://journal-isi.org/index.php/isi

Published By DRPM-UBD

\title{
Analysis of the Use of Cellular Operators Using the Analytic Hierarchy Process Method
}

\section{Analisis Penggunaan Operator Seluler Menggunakan Metode Analytic Hierarchy Process}

\author{
Ari Muzakir ${ }^{1}$ Usman Ependi ${ }^{2}$ \\ 1,2Informatics Department, Universitas Bina Darma, Palembang, Indonesia \\ Email: arimuzakir@binadarma.ac.id ${ }^{1}$, u.ependi@binadarma.ac.id ${ }^{2}$
}

\begin{abstract}
The development of technology in the telecommunications sector is now easier to be enjoyed by the community. Almost all regions have been able to enjoy the ease of access to information through telecommunications networks. Telecommunications service providers certainly have competed in such a way as to be able to hold users to remain loyal to the provider used. From several surveys conducted, there are still many users who cannot be loyal to use the services of these providers. The increasing number of communication network providers makes users more choices. Various ways are carried out by communication network providers to maintain their users such as giving bonuses, providing cheap rates, increasing services to the regions. In this study will focus on the level of customer satisfaction with cellular operators with a variety of criteria that have been prepared which will be a consideration for users in using these cellular operators. This research will use the AHP method (Analytic Hierarchy Process) to find out which cellular operators are the most superior based on the judgment of the user with various criteria each. So that in the end it will be known which cellular operators will be selected and purchased by consumers according to their respective needs. The results of this study show that based on the bonus, IM3 is the best with a weight of 0.21712 . Then based on the price rate, a tri card with a weight of 0.16565 . Furthermore, the service criteria show a better Sympathy card with a weight of 0.21311 .
\end{abstract}

Keywords: Analytic Hierarchy Process, telecommunications service providers, customer satisfaction, cellular operators

\section{PENDAHULUAN}

Perkembangan informasi dan telekomunikasi yang begitu cepat seperti saat ini menuntut setiap orang harus memiliki sebuah alat bantu dalam berkomunikasi baik itu jarak jauh maupun jarak pendek. Alat bantu yang kita kenal dengan bandphone atau gawai tersebut tidak hanya berfungsi untuk berkomunikasi saja

This work is licensed under a Creative Commons Attribution 4.0 International License. 
tetapi juga memiliki fungsi yang lain seperti untuk berselancar di dunia maya, media sosial, menonton film dan video, mendengarkan musik, bermain game, transaksi jual beli / e-commerce, bahkan kegiatan - kegiatan yang pada beberapa tahun yang lalu harus dilakukan dengan cara yang manual atau konvensional saat ini juga bisa dengan mudah diatasi dengan penggunaan handphone atau gawai seperti memesan kendaraan dan memesan makanan tanpa harus susah payah dengan melakukan kegiatan fisik [1][2]. Dengan berbagi kegunaan dan fungsinya tersebut, sebuah handphone atau gawai tentunya dituntut memiliki teknologi yang tinggi dan mumpuni untuk mendukung segala macam kebutuhan pemakainya. Namun lebih dari itu, hal utama yang harus diperhatikan adalah kualitas dari operator seluler yang digunakan agar semakin memperkaya kegunaan dan meningkatkan kapabilitas dari handphone itu sendiri [3].

Pada penelitian ini akan fokus mengenai tingkat kepuasan pelanggan terhadap operator seluler dengan berbagai macam kriteria yang telah dipersiapkan yang akan menjadi bahan pertimbangan bagi user dalam menggunakan operator seluler tersebut. Penelitian ini akan menggunakan metode AHP (Analityc Hierarchy) Process) untuk mengetahui operator seluler mana yang paling unggul berdasarkan judgment dari user dengan berbagai kriterianya masing - masing. Metode AHP digunakan sebagai model pendukung keputusan dengan menguraikan permasalahan yang multi faktor atau multi kriteria yang dapat dikatakan kompleks menjadi suatu hirarki. Hirarki didefinisikan sebagai suatu representasi dari sebuah permasalahan yang kompleks menjadi suatu struktur multi-level [4][5]. Sehingga pada akhirnya akan diketahui operator seluler mana yang akan dipilih dan dibeli oleh konsumen sesui dengan kebutuhan mereka masingmasing. Adapun operator seluler yang dipilih dalam penelitian ini adalah operator yang mayoritas digunakan oleh konsumen di Indonesia seperti Telkomsel (Simpati, AS), XL, Indosat Ooredoo, Axis, 3, serta Smartfren. Untuk pengelompokan kriteria berdasarkan identifikasi kebutuhan konsumen seperti faktor harga, kualitas sinyal, bonus, serta layanan yang diperoleh konsumen.

\section{METODOLOGI}

Pada penelitian ini menggunakan metode penelitian deskriptif. Metode ini dipilih karena kemudahan dalam proses menjelaskan suatu kejadian yang sedang terjadi [6]. Kemudian itu, model penelitian desktiptif ini merupakan suatu penelitian yang bertujuan untuk memberikan atau menjabarkan suatu keadaan atau fenomena yang terjadi saat ini dengan menggunakan prosedur ilmiah untuk menjawab masalah secara aktual [7][6].

30 | Analysis of the Use of Cellular Operators Using the Analytic Hierarchy... 


\subsection{Metode Pengumpulan Data}

Dalam melakukan pengumpulan data menggunakan beberapa tahapan antara lain:

1. Studi Pustaka yang merupakan metode pengumpulan data melalui referensi ilmiah seperti buku, jurnal, dan informasi online lainnya.

2. Wawancara. Cara ini dilakukan dengan mencari inforamasi terkait dengan pengguna operator telekomunikasi yang ada.

3. Kuisioner. Pengumpulan data ini bertujuan untuk mengkoleksi informasi dari pengguna secara langsung melalui pengisian lembar kuisioner yang diberikan kepada para responden [8].

\subsection{Pola Pikir}

Dalam melakukan penelitian ini menggunakan beberapa tahapan seperti pada Gambar 1 berikut. Dengan dilakukannya proses mapping ini diharapkan proses penyelesaian alur penelitian ini lebih tersistematis.

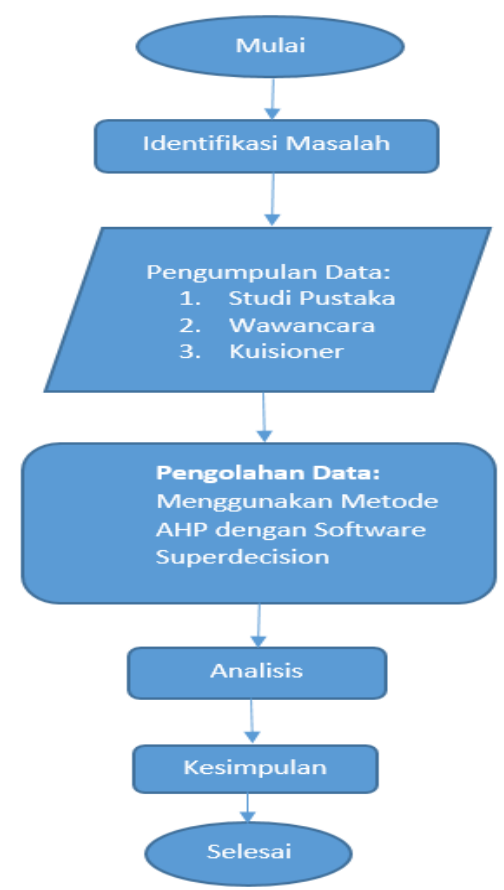

Gambar 1. Flowchart yang diterapkan dalam penelitian

Langkah yang dilakukan dalam pengambilan keputusan mengenai operator seluler yang terbaik yaitu dengan menentukan variabel-variabel kriteria, subkriteria serta alternatif yang akan digunakan. Adapun kriteria yang digunakan yaitu kriteria bonus, kriteria harga, kriteria layanan, dan kriteria kualitas sinyal. 
Selanjutnya untuk alternatif yang diberikan yaitu operator seluler yang mayoritas digunakan oleh konsumen di Indonesia seperti Telkomsel (Simpati dan AS), XL Axiata, Indosat Ooredoo (IM3), 3, Axis, dan Smartfren. Hasil dari analisis tersebut dapat dilihat pada Gambar 2 berikut ini.
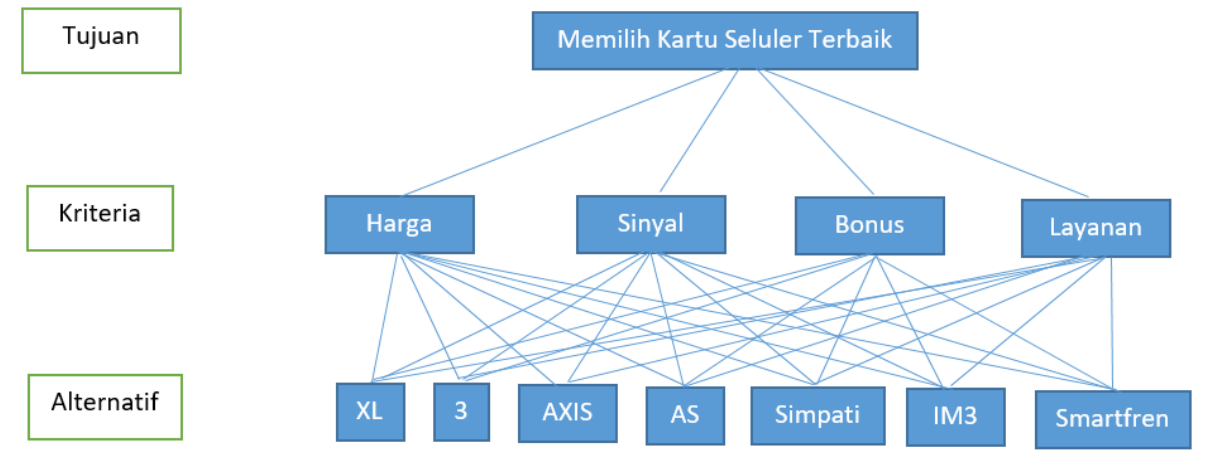

Gambar 2. Penentuan Kriteria dan Alternatif

a) Kriteria

1. Kriteria Bonus: hadiah yang diberikan sebagai bentuk atau strategi promosi seperti:
a. Promo intenet murah.
b. Promo sms, dan
c. Promo bicara.

2. Kriteria Harga: nilai pertukaran atas manfaat produk seperti:
a. SMS.
b. Telepon, dan
c. Paket data internet.

3. Kriteria layanan: manfaat lain yang ditawarkan pihak operator untuk memudahkan pelanggan seperti:
a. Call center.
b. Customer service.

4. Kriteria Kualitas Sinyal: ini merupakan hal yang sangat penting bagi konsumen karena kemampuan sinyal kuat menjadi dasar pemilihan masyarakat. Adapun kriteria kualitas sinyal ini meliputi:
a. Sinyal kuat.
b. Kualitas sinyal, serta
c. Jaringan yang terluas.

b) Alternatif

Dalam pemilihan alternatif ini mengacu pada berbagai fitur dan layanan yang disediakan operator. Berbagai strategi pemasaran yang dilakukan operator melalui produk unggulan mereka seperti promo-promo yang menarik konsumen ditambah lagi kualitas sinyal yang sudah merata di seluruh daerah, promo murah SMS maupun telepon 
yang ditawarkan ditambah promo-promo menarik untuk kalangan remaja. Dari kriteria yang telah disebutkan sebelumnya didapatkan beberapa alternatif-alternatif yang biasa digunakan masyarakat antara lain:
1. Kartu Simpati
2. Kartu AS
3. Kartu XL
4. Kartu IM3
5. Kartu 3
6. Kartu Axis
7. Kartu Smartfren

\subsection{Analisis AHP}

Langkah-langkah dalam melakukan analisis data yaitu [9][10]:

1. Mengidentifikasi, yaitu mengidentifikasi permasalahan dan menentukan solusi yang diinginkan. Identifikasi dilakukan dengan mempelajari dan berdiskusi dengan pakar yang paham mengenai permasalahan.

2. Penyusunan hirarki, diawali dengan tujuan umum dan dilanjutkan dengan kriteria dan sub kriteria seperti pada Gambar 2.

3. Membuat matrik perbandingan berpasangan yang menggambarkan pengaruh relatif setiap elemen terhadap masing-masing tujuan atau kriteria yang setingkat diatasnya. Untuk menilai perbandingan tingkat kepentingan dilakukan penetapan skala kuantitatif dari skala 1 sampai 9 seperti pada Tabel 1. Matrik perbandingan berpasangan (painvise comparisons matrix) dibuat berdasarkan masukan dari pengguna (comparative judgement) dengan menilai tingkat kepentingan kriteria dibanding kriteria lain.

4. Menentukan pembobotan vektor dengan cara:

a. Normalisasi setiap komom dalam matrik dengan persamaan 1 berikut. $\sum_{\mathrm{i}} \mathrm{a}_{\mathrm{ij}}=1$

a $\boldsymbol{i} \boldsymbol{j}$ adalah elemen matriks A.

b. Untuk setiap baris dalam matrik dihitung nilai rata-rata (vektor eigen) seperti persamaan 2 berikut. $\mathrm{Wi}=1 / \mathrm{n} \sum \mathrm{a}_{\mathrm{ij}}$

5. Melakukan pengujian konsistensi terhadap hasil perbandingan.

Jika A adalah matriks perbandingan berpasangan dan W adalah vektor bobot, maka konsistensi dari A dapat diuji dengan cara :

a. Menghitung elemen dengan persamaan 3 berikut. $\mathrm{t}=1 / \mathrm{n} \sum \mathrm{n} 1\left(\right.$ elemen ke i pada $(\mathrm{A})\left(\mathrm{W}^{\mathrm{t}}\right) /$ elemen ke i pada $\left.\mathrm{w}^{\mathrm{t}}\right)$

b. Menghitung Consistency Index (CI) melalui persamaan 4 berikut. $\mathrm{CI}=\mathrm{t}-\mathrm{n} / \mathrm{n}-1$

c. Periksa Consistency Ratio (CR) melalui persamaan 5 berikut. $\mathrm{CR}=\mathrm{CI} / \mathrm{RI}$ Jika $\mathrm{CR}<0,1$ maka A konsisten. 
Vol. 1, No. 1, March 2019

p-ISSN: 2656-5935 http://journal-isi.org/index.php/isi e-ISSN: 2656-4882

Jika CR $>0,1$ maka A tidak konsisten.

Nilai RI $=$ nilai indeks random berdasarkan Tabel 2 berikut.

Tabel 2. Random Index [10]

\begin{tabular}{lcccccccccccccc}
\hline $\boldsymbol{N}$ & 12 & $\mathbf{3}$ & $\mathbf{4}$ & $\mathbf{5}$ & $\mathbf{6}$ & $\mathbf{7}$ & $\boldsymbol{8}$ & $\mathbf{9}$ & $\mathbf{1 0}$ & $\mathbf{1 1}$ & $\mathbf{1 2}$ & $\mathbf{1 3}$ & $\mathbf{1 4}$ & $\mathbf{1 5}$ \\
\hline $\boldsymbol{R I} 0$ & 0 & 0.58 & 0.9 & 1.12 & 1.24 & 1.32 & 1.41 & 1.45 & 1.49 & 1.51 & 1.48 & 1.56 & 1.57 & 1.59 \\
\hline
\end{tabular}

6. Menentukan bobot global jika terdapat sub kriteria.

7. Menentukan ranking alternatif melalui persamaan 6 berikut. $\mathrm{S}_{\mathrm{j}}=\sum_{\mathrm{i}}\left(\mathrm{S}_{\mathrm{i}}\right)\left(\mathrm{W}_{\mathrm{i}}\right)$

\section{HASIL DAN PEMBAHASAN}

Proses pengolahan data hasil pengisian kuisioner yang dilakukan untuk menentukan alternatif operator kartu seluler yang digunakan oleh masyarakat menggunakan software superdecision. Pada Gambar 3 berikut menunjukkan contoh formulir isian kuesioner.

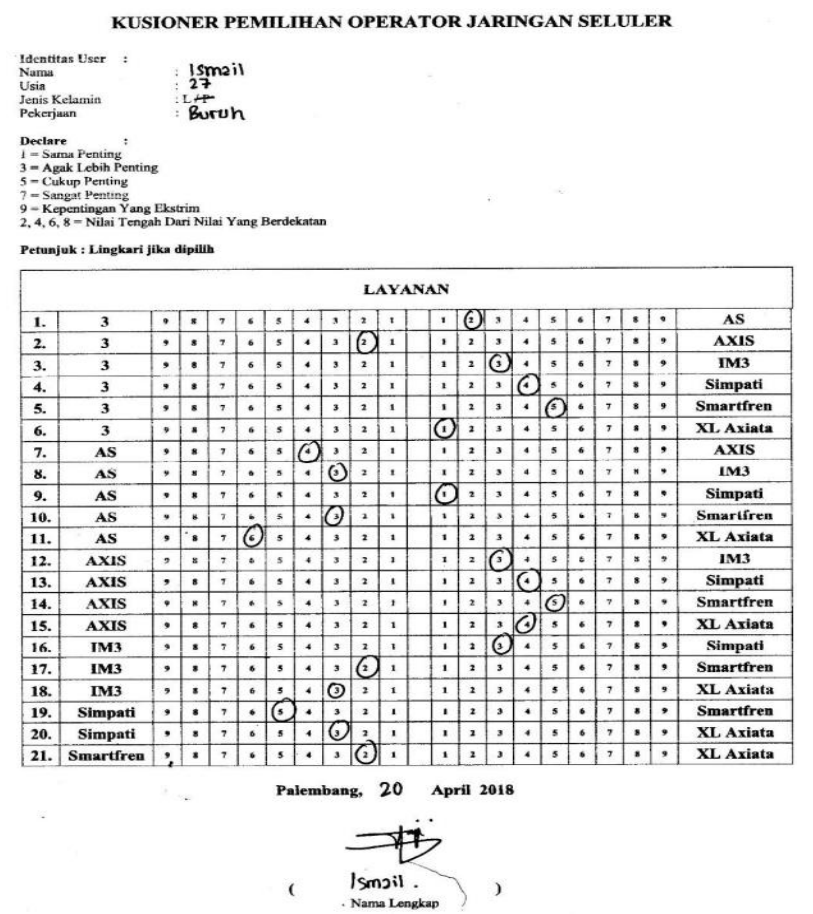

Gambar 3. Formulir Kuesioner dengan Matrik Perbandingan

Selanjutnya data-data hasil kuesioner tersebut akan di olah menggunakan software superdecision sehingga menghasilkan suatu sistem keputusan yang dapat di gunakan sebagai alternatif. Pada Gambar 4 berikut menunjukkan softwrare superdecision.

34 | Analysis of the Use of Cellular Operators Using the Analytic Hierarchy... 
Vol. 1, No. 1, March 2019

p-ISSN: 2656-5935 http://journal-isi.org/index.php/isi e-ISSN: 2656-4882

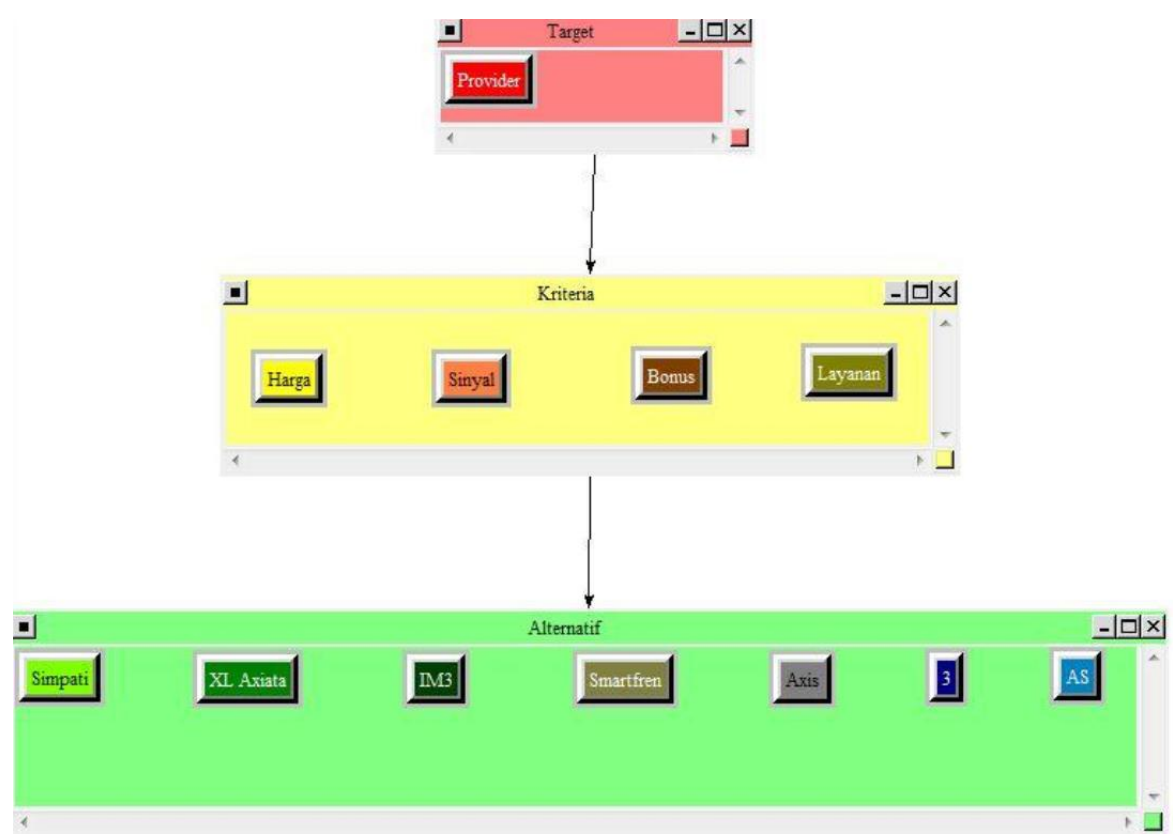

Gambar 4. Penggunaan Software Superdecision dalam Pengolahan Data

\subsection{Perhitungan Pembobotan Hirarki Kriteria}

Perhitungan ini memperlihatkan seberapa besar prioritas utama dari kriteria-kritera untuk menentukan alternatif kartu seluler yang baik. Proses perhitungan ini menghasilkan suatu rule baru yang dapat dijadikan alternatif.

a. Berdasarkan kriteria bonus

Dari hasil pengolahan data kuesioner yang di isi oleh 21 responden, comparation kriteria bonus menunjukkan perbandingan antara cluster alternatif bahwa kartu seluler IM3 jauh lebih penting daripada kartu Axis dari sisi bonus yang diberikan.

\begin{tabular}{|l|l|l|}
\hline 3 & & 0.16878 \\
\hline AS & & 0.10197 \\
\hline Axis & & 0.09628 \\
\hline IM3 & & 0.21712 \\
\hline Simpati & & 0.10429 \\
\hline Smartfren & & 0.11968 \\
\hline XL Axiata & & 0.19187 \\
\hline
\end{tabular}

Gambar 5. Grafik analisis Pengolahan berdasarkan kriteria Bonus

b. Berdasarkan kriteria harga

Dari hasil pengolahan data kuesioner, comparation kriteria harga menunjukkan perbandingan antara cluster alternatif bahwa kartu XL Axiata sama dengan cukup penting daripada kartu Smartfren. 
Vol. 1, No. 1, March 2019

p-ISSN: 2656-5935 http://journal-isi.org/index.php/isi e-ISSN: 2656-4882

\begin{tabular}{|l|l|l|}
\hline 3 & & 0.16565 \\
\hline AS & & 0.14315 \\
\hline Axis & & 0.15017 \\
\hline IM3 & & 0.06773 \\
\hline Simpati & & 0.14313 \\
\hline Smartfren & & 0.16432 \\
\hline XL Axiata & & 0.16585 \\
\hline
\end{tabular}

Gambar 6. Grafik analisis Pengolahan berdasarkan kriteria Harga

c. Berdasarkan kriteria layanan

Dari hasil pengolahan data kuesioner yang di isi oleh 21 responden, comparation kriteria layanan menunjukkan perbandingan antara cluster alternatif bahwa kartu seluler XL Axiata jauh lebih penting daripada smartfren.

\begin{tabular}{|l|l|l|}
\hline 3 & & 0.18405 \\
\hline AS & & 0.15640 \\
\hline Axis & & 0.10449 \\
\hline IM3 & & 0.08136 \\
\hline Simpati & & 0.21311 \\
\hline Smartfren & & 0.14074 \\
\hline XL Axiata & & 0.11985 \\
\hline
\end{tabular}

Gambar 7. Grafik analisis Pengolahan berdasarkan kriteria Layanan

\section{d. Berdasarkan kriteria sinyal}

Dari hasil pengolahan data kuesioner yang di isi oleh 21 responden, comparation kriteria layanan menunjukkan perbandingan antara cluster alternatif bahwa kartu seluler Smartfren jauh lebih penting daripada XL Axiata.

\begin{tabular}{|l|l|l|}
\hline 3 & & 0.11741 \\
\hline AS & & 0.17495 \\
\hline Axis & & 0.09779 \\
\hline IM3 & & 0.17280 \\
\hline Simpati & & 0.10414 \\
\hline Smartfren & & 0.19303 \\
\hline XL Axiata & & 0.13989 \\
\hline
\end{tabular}

Gambar 8. Grafik analisis Pengolahan berdasarkan kriteria Sinyal

\subsection{Hasil Analisis}

Dari perhitungan pembobotan diatas, maka dapat dilakukan analisis berdasarkan survei yang dilakukan dan diolah menggunakan software super decision seperti direkap pada tabel berikut ini.

36 | Analysis of the Use of Cellular Operators Using the Analytic Hierarchy... 
Tabel 3. Hasil Analisis

\begin{tabular}{|c|c|c|c|}
\hline \multicolumn{4}{|c|}{ Hasil analisis berdasarkan rating kriteria yang dipilih pengguna } \\
\hline Kriteria bonus & Kriteria harga & Kriteria layanan & Kriteria sinyal \\
\hline 1. IM3 & 1. XL Axiata & 1. Simpati & 1. Smartfren \\
\hline 2. $\mathrm{XL}$ & 2. Smartfren & 2. 3 (Tri) & AS \\
\hline Axiata & 3. 3 (Tri) & 3. AS & IM3 \\
\hline 3. 3 (Tri) & 4. Axis & 4. Smartfren & Simpati \\
\hline 4. Smartfre & 5. AS & Axis & XL Axiata \\
\hline $\mathrm{n}$ & 6. Simpati & 6. XL Axiata & Axis \\
\hline Simpati & 7. IM3 & 7. IM3 & 3 (Tri) \\
\hline As & & & \\
\hline 7. Axis & & & \\
\hline
\end{tabular}

\section{KESIMPULAN}

Setelah mengetahui apa yang dibutuhkan oleh konsumen berdasarkan hasil dari survei, maka sudah sebaiknya perusahaan operator seluler memperhatikannya kemudian ditindaklanjuti dengan peningkatan kualitas agar terjadi hubungan simbiosis mutualisme antara perusahaan operator seluler dan konsumen, yaitu konsumen akan merasa puas dan perusahaan akan mendapatkan keuntungan.

\section{DAFTAR PUSTAKA}

[1] Said Agung Prabowo; Antono Adhi; Agus Setiawan, "PENENTUAN OPERATOR KARTU SELULER TERBAIK DENGAN METODE AHP(ANALYTICHAL HIERARCHY PROCESS)," pp. 1-9, 2003.

[2] B. Prasetyo, W. L. Y. Saptomo, and S. Siswanti, "Sistem Pendukung Keputusan Pemilihan Paket Internet Operator Telekomunikasi Dengan Metode Ahp (Analytical Hierarchy Process)," J. Teknol. Inf. dan Komun., vol. 1, no. 2, pp. 7-12, 2013.

[3] Suyatno, "PENGGUNAAN DAN PENERAPAN TEKNOLOGI INFORMASI SEBAGAI SISTEM PENDUKUNG KEPUTUSAN ( SPK ) ( Studi Kasus di Lembaga Pemerintahan Daerah Kabupaten Jepara )," J. Inform. J. Pengemb. IT, vol. 1, no. 2, pp. 52-61, 2016.

[4] A. B. Prasetyo and D. Kriestanto, "Analytical Hierarchy Proccess (Ahp) Untuk Membangun Mesin Pencari Data Lulusan Perguruan Tinggi Berdasarkan Kebutuhan Pengguna Lulusan," Simetris J. Tek. Mesin, Elektro dan Ilmu Komput., vol. 7, no. 1, p. 123, 2017.

[5] K. Suryadi and M. A. Ramdhani, "Sistem Pendukung Keputusan," PT Remaja Rosdakarya, Bandung, 1998.

[6] Sugiyono, "Metode Penelitian Manajemen," Alfabeta, 2013. 
[7] S. Nasution, "Metode Penelitian," Jakarta: Rineka Cipta, 2002.

[8] A. Muzakir and C. D. Kusmindari, "Design of Push-Up Detector Applications Using Quality Function Development and Anthropometry For Movement Error Detection," Sci. J. Informatics, vol. 5, no. 2, pp. 248257, 2018.

[9] I. Santoso, M. Sa'adah, and S. Wijana, "QFD and Fuzzy AHP for Formulating Product Concept of Probiotic Beverages for Diabetic," TELKOMNIKA (Telecommunication Comput. Electron. Control., 2017.

[10] R. D. F. S. M. Russo and R. Camanho, "Criteria in AHP: A systematic review of literature," in Procedia Computer Science, 2015.

38 | Analysis of the Use of Cellular Operators Using the Analytic Hierarchy... 